\title{
Effects of L-carnitine supplementation of diets differing in energy levels on performance, abdominal fat content, and yield and composition of edible meat of broilers
}

\author{
Mahmoud H. Rabie† and Mihály Szilágyi* \\ Department of Biochemistry, Research Institute for Animal Breeding \& Nutrition, H-2053 Herceghalom, Hungary
}

(Received 23 November 1997 - Revised 2 April 1998 - Accepted 23 April 1998)

\begin{abstract}
Responses to supplemental dietary L-carnitine of broilers fed on diets with different levels of metabolizable energy (ME) were investigated using growth performance and some carcass measurements. Three isonitrogenous diets containing $13.5,12.8$ or $12.2 \mathrm{MJ} \mathrm{ME} / \mathrm{kg}$ were formulated, with or without supplemental L-carnitine $(50 \mathrm{mg} / \mathrm{kg})$ and fed ad libitum from 18 to $53 \mathrm{~d}$ of age. Supplemental L-carnitine increased body-weight gain (BWG) and improved feed conversion (FC) during the first 2 weeks of study. FC was also improved during the fourth week of the experiment. Weights of breast yield and thigh meat yield were significantly increased, whereas quantity and percentage of abdominal fat were reduced by supplemental L-carnitine. A significant interaction between supplemental dietary L-carnitine and dietary energy level was noted for BWG and FC during the second week of study.
\end{abstract}

L-Carnitine: Metabolizable energy: Growth: Carcass quality

Excessive fatness is one of the undesirable consequences of selection for increased growth of modern broiler chickens. Accumulation of fat in carcasses of broilers, particularly in abdominal and visceral areas, represents a waste product to consumers who are increasingly concerned about the nutritional and health aspects of their food. Such obese broilers will be unattractive to those consumers, and thus will lead to decreased saleability, which in turn reduces the net returns for the producers. In addition, from the nutritional point of view, the deposition of abdominal fat is a non-profitable conversion of dietary energy. Moreover, broilers containing excessive abdominal fat are less desirable also for the processors, because the partially removed fat will increase the waste-disposal problems during the processing procedures.

Fat deposition in modern broilers depends to a great extent on their voracious appetite. For this reason, nutritionists continuously try to mediate this problem by means of dietary manipulations, in order to achieve the desired characteristics of growth and carcass composition. In addition to optimizing growth rate and feed utilization, there is also an ongoing demand to maximize growth of lean tissue and to minimize the undesirable fat accumulation in broilers at marketing age. Since carcass fat deposition can be altered through modifying the energy intake of the broiler (Summers \& Leeson, 1984; Leeson et al. 1996a,b), it seems reasonable that some positive effects may be obtained by reducing the energy level in broiler diets fed during the growing and finishing periods when the birds consume the major portion of their overall feed consumption.

L-Carnitine $(\beta-\mathrm{OH}-\gamma-\mathrm{N}$-trimethylaminobutyric acid) is a small-molecular-weight water-soluble quaternary amine which occurs naturally in micro-organisms, plants and animals (Bremer, 1983). Its concentrations in animals vary according to species (Szilágyi et al. 1992), tissue type (Bremer, 1983; Rinaudo et al. 1991) and nutritional status of the animal (Khan \& Bamji, 1979). Dietary lysine and methionine are the exogenous precursors for L-carnitine biosynthesis, in the presence of $\mathrm{Fe}^{2+}$ and a number of vitamins (ascorbate, niacin and pyridoxine) which are required as cofactors for the enzymes involved in the metabolic pathway of L-carnitine (Sándor et al. 1983; Feller \& Rudman, 1988; Rebouche, 1991; Leibetseder, 1995). However, little L-carnitine has been reported to be found in cereal grains and their by-products (Baumgartner \& Blum, 1993); however, these feed ingredients usually constitute the major portion of poultry diets.

L-Carnitine promotes the mitochondrial $\beta$-oxidation of long-chain fatty acids by facilitating their transfer across the inner mitochondrial membrane. It also facilitates the removal from mitochondria of short-chain and medium-chain fatty acids that accumulate as a result of normal and abnormal metabolism (Bremer, 1983; Rebouche, 1992).

\footnotetext{
Abbreviations: BWG, body-weight gain; FC, feed conversion; ME, metabolizable energy.

*Corresponding author: Professor Mihály Szilágyi, fax +36 23319133.

$\dagger$ Present address: Department of Poultry Production, Faculty of Agriculture, Mansoura University, El-Mansoura, Egypt.
} 
Several studies on pigs, fish, quail (Coturnix coturnix), foals and broiler chickens have shown that growth performance was significantly improved by feeding dietary L-carnitine (Santulli \& D'Amelio, 1986; Weeden et al. 1991; Lettner et al. 1992; Schuhmacher et al. 1993; Torreele et al. 1993; Hausenblasz et al. 1996; Rabie et al. 1997c,d). With laying hens, supplemental dietary L-carnitine resulted in an improvement in the albumen quality of eggs, measured as albumen height and Haugh unit score, during the early and late stages of laying period (Rabie et al. 1997a,b). Leibetseder (1995) has reported that egg hatchability increased from 83 to $87 \%$ and from 82.4 to $85.3 \%$ when broiler breeders were fed on diets supplemented with L-carnitine at levels of 50 and $100 \mathrm{mg} / \mathrm{kg}$ diet respectively. In contrast, some investigators failed to observe any favourable responses to added dietary carnitine (Cartwright, 1986; Barker \& Sell, 1994).

In view of the key role of L-carnitine in energy metabolism, we have hypothesized that its incorporation into broiler diets may contribute to a reduction in the degree of adiposity in broiler chickens, particularly when they are fed on diets with different energy contents. Dietary energy level is usually increased by the addition of fat. Thus, if added L-carnitine could enhance the utilization of dietary fat, the other dietary components would be metabolized in favour of protein accretion (deposition). Thus, the purpose of the current study was to investigate the responses to supplemental dietary L-carnitine of broiler chickens fed on diets with different levels of metabolizable energy (ME) during the growing and finishing periods from 18 to $53 \mathrm{~d}$ of age. The responses were measured in terms of weekly feed intake, energy intake, body-weight gain (BWG), feed conversion (feed intake:BWG; FC), carcass yield, abdominal fat content and composition of the liver as well as the breast and thigh meat of broilers.

\section{Materials and methods \\ Birds and diets}

A total of 180 1-d-old Hybro broiler chicks (HE-ROS Ltd., Ócsa, Hungary) were used in the present study. The chicks were fed on a commercial starter diet from 1-d-old to $18 \mathrm{~d}$ of age and then switched to the experimental diets. Three isonitrogenous diets $(180 \mathrm{~g}$ crude protein $(\mathrm{N} \times 6 \cdot 25) / \mathrm{kg})$ were formulated to contain $13 \cdot 5,12.8$ or $12 \cdot 2 \mathrm{MJ} \mathrm{ME} / \mathrm{kg}$ (Table 1), with or without supplemental L-carnitine $(50 \mathrm{mg} /$ $\mathrm{kg} \mathrm{diet}$ ), in the form of Carniking ${ }^{\circledR}$ (LONZA Ltd., Basel, Switzerland); thus providing six experimental diets. Except for energy level, these diets were formulated to meet or slightly exceed the nutrient requirements of broilers, as specified by the National Research Council (1984). The diet containing $13.5 \mathrm{MJ} \mathrm{ME} / \mathrm{kg}$ was considered to serve as a control diet. All diets were offered to the birds in the form of mash. L-Carnitine was incorporated into diets at the expense of maize.

Table 1. Composition and proximate analyses $(\mathrm{g} / \mathrm{kg})$ of the basal diets fed to broilers*

\begin{tabular}{|c|c|c|c|}
\hline Dietary metabolizable energy levels $(\mathrm{MJ} / \mathrm{kg}) \ldots$ & 13.5 & $12 \cdot 8$ & $12 \cdot 2$ \\
\hline \multicolumn{4}{|l|}{ Ingredients } \\
\hline Yellow maize & $507 \cdot 3$ & $613 \cdot 4$ & $203 \cdot 2$ \\
\hline Soyabean meal ( $470 \mathrm{~g}$ crude protein $\mathrm{N} \times 6 \cdot 25 / \mathrm{kg}$ ) & $241 \cdot 1$ & $230 \cdot 2$ & $169 \cdot 0$ \\
\hline Animal-vegetable fat $\dagger$ & $110 \cdot 5$ & $15 \cdot 1$ & 0.0 \\
\hline Wheat & $100 \cdot 0$ & $100 \cdot 0$ & $585 \cdot 4$ \\
\hline Limestone & $16 \cdot 2$ & $16 \cdot 4$ & $15 \cdot 9$ \\
\hline Monocalcium phosphate & $12 \cdot 7$ & $12 \cdot 2$ & 11.9 \\
\hline DL-Methionine & $2 \cdot 7$ & $2 \cdot 6$ & $2 \cdot 9$ \\
\hline L-Lysine hydrochloride & 1.5 & $1 \cdot 8$ & 3.7 \\
\hline Total & $1000 \cdot 0$ & $1000 \cdot 0$ & $1000 \cdot 0$ \\
\hline \multicolumn{4}{|l|}{ Calculated analyses } \\
\hline Diethyl ether extract & 74.7 & $41 \cdot 2$ & $25 \cdot 6$ \\
\hline Crude fibre & $31 \cdot 0$ & 31.4 & 32.9 \\
\hline Methionine & $5 \cdot 3$ & $5 \cdot 3$ & 5.5 \\
\hline Threonine & $6 \cdot 6$ & $6 \cdot 7$ & $6 \cdot 0$ \\
\hline Metabolizable energy: MJ/kg & 13.5 & $12 \cdot 8$ & $12 \cdot 2$ \\
\hline $\mathrm{kcal} / \mathrm{kg}$ & $3226 \cdot 5$ & $3059 \cdot 2$ & $2915 \cdot 8$ \\
\hline Energy $(\mathrm{kcal})$ : protein $(\mathrm{g} / \mathrm{kg}) \ddagger$ & $17 \cdot 9$ & $17 \cdot 0$ & $16 \cdot 2$ \\
\hline \multicolumn{4}{|l|}{ Determined analyses } \\
\hline DM & $940 \cdot 5$ & 935.5 & $950 \cdot 0$ \\
\hline Crude protein & $180 \cdot 2$ & $180 \cdot 5$ & 179.5 \\
\hline Diethyl ether extract & 74.2 & 41.0 & 25.9 \\
\hline Crude fibre & $31 \cdot 7$ & $39 \cdot 7$ & 33.0 \\
\hline Ash & 59.5 & $51 \cdot 0$ & 50.0 \\
\hline Gross energy (MJ/kg DM) & $16 \cdot 3$ & $15 \cdot 5$ & 14.7 \\
\hline
\end{tabular}




\section{Housing and management}

During the starter period, chicks were kept in conventional wire-floored brooding batteries (placed in an open-sided growing house equipped with a gas heating system) and provided with feed and water on an ad libitum basis.

At $18 \mathrm{~d}$ of age, all chicks were wing-banded, weighed individually, randomly allocated to six experimental groups and transferred to three-tier double-sided wire floor rearing batteries equipped with nipple drinkers, with continuous lighting throughout the course of experiment. Each battery consisted of twelve compartments. Each experimental group of ten birds was replicated three times and housed in battery compartments, each measuring $600 \mathrm{~mm} \times$ $900 \mathrm{~mm}$. Birds had free access to feed and water throughout the experimental period, from 18 to $53 \mathrm{~d}$ of age.

\section{Measurements of responses}

Live performance. The performance of broiler chickens was evaluated in terms of weekly feed intake, energy intake, BWG and FC, as influenced by dietary L-carnitine supplementation to isonitrogenous diets with different energy levels during the growing and finishing periods.

Individual live body weights of the chicks were recorded at the beginning of experiment (18-d-old) and on a weekly basis thereafter. Weekly records of feed intake for each of the replicate groups for each treatment were also maintained. Data recorded for weekly feed intake were used to calculate mean energy intake and FC (feed intake: BWG).

Carcass yield and quality. As with all broiler chickens, birds destined for slaughter had free access to feed and water, in order to avoid a possible effect of feed withdrawal for a period of time before slaughter on the fat content of liver and/or other tissues, which may mask some of the effects of factors in question or confound the interpretation of the results obtained.

In order to examine the effect of L-carnitine on fat deposition, we delayed the time of slaughter beyond the normal age used in common practice (i.e. to $53 \mathrm{~d}$ of age). At this stage, we made the following measurements: carcass yield and components (weights and percentages of eviscerated carcass, giblets, total edible parts, breast yield including bones, thigh plus drumstick yield including bones, breast meat yield and thigh plus drumstick meat yield), abdominal fat content (as an absolute weight and as a percentage of body weight) and composition of edible meat of broilers (in terms of DM, crude protein and diethyl ether extract contents of liver, breast meat and thigh plus drumstick meat). Six birds from each treatment, with body weights approximating to the mean value of the representative group, were selected and killed by decapitation. The carcasses were immediately scalded, feather picked and eviscerated, and then chilled overnight in a refrigerator at $4^{\circ}$ in order to facilitate the removal of the abdominal fat pad. The dissection of carcasses was performed according to the procedure described by Jensen (1984), and the abdominal fat pad was removed according to the method outlined by Fancher \& Jensen (1989). From one side of breast and one thigh plus drumstick of each bird, meat (with skin) was excised and weighed separately. Total meat yields for both breast and thighs (including drumsticks) were calculated as the amount of meat excised $\times 2$. Weights of the dissected parts of the carcasses and of breast and thigh meat were determined to the nearest $1 \mathrm{~g}$, while those of the abdominal fat pad and organs (liver, heart and gizzard) were measured to the nearest $0 \cdot 1 \mathrm{~g}$. Samples of liver, breast meat and thigh plus drumstick meat were removed and frozen $\left(-20^{\circ}\right)$ until analysed.

\section{Laboratory analyses}

The frozen samples of liver and breast and thigh meat were dried in a forced-draft oven at $65^{\circ}$, ground and used for chemical analysis. The proximate analyses for both the basal experimental diets and meat samples of breast, thigh and liver were carried out according to the official methods of analysis (Association of Official Analytical Chemists, 1980). The gross energy contents of the basal experimental diets were determined using an adiabatic oxygen bomb calorimeter.

\section{Statistical analysis}

A completely randomized design in factorial arrangement of treatments, three levels of dietary $\mathrm{ME}(13.5,12.8$ or $12.2 \mathrm{MJ} \mathrm{ME} / \mathrm{kg}$ ) with or without L-carnitine supplementation $(50 \mathrm{mg} / \mathrm{kg}$ diet), was used to separate the effect of dietary energy level from that of L-carnitine supplementation. The statistical processing of data was performed using the Statgraphics Program (Statistical Graphics Corporation, 1991) based on a multifactorial ANOVA, with $P \leqslant 0.05$ considered to be significant. After ANOVA, significantly different means for each variable were separated using Duncan's multiple-range test (Duncan, 1955).

\section{Results}

Table 2 shows values for feed and energy intakes of broilers fed on L-carnitine-supplemented diets with different energy levels during the growing and finishing periods from 18 to $53 \mathrm{~d}$ of age. Neither feed nor energy intakes were affected by dietary L-carnitine supplementation. However, feed intake was significantly increased by decreasing the dietary energy level below $13.5 \mathrm{MJ} \mathrm{ME} / \mathrm{kg}$ during the period from 18 to $32 \mathrm{~d}$ of age and over the experimental feeding period, with or without added dietary L-carnitine. Energy intake of birds fed on the lowest level of dietary energy (12.2 MJ $\mathrm{ME} / \mathrm{kg}$ diet) was significantly lower than that of birds fed on the highest dietary energy level (13.5 MJ ME/kg diet) in the feeding period $46-53 \mathrm{~d}$ of age. In the other feeding periods, dietary energy level had no effect on energy intake, irrespective of L-carnitine supplementation. There was no interaction between dietary energy level and supplemental L-carnitine with respect to feed or energy intakes of broilers throughout the experimental period.

Weekly and overall means for BWG and FC of broilers fed on the experimental diets from 18 to $53 \mathrm{~d}$ of age are presented in Table 3 . The addition of L-carnitine to growerfinisher diets of broilers resulted in significant increases in BWG and FC, independent of dietary energy level. Higher values for BWG in response to added dietary L-carnitine 


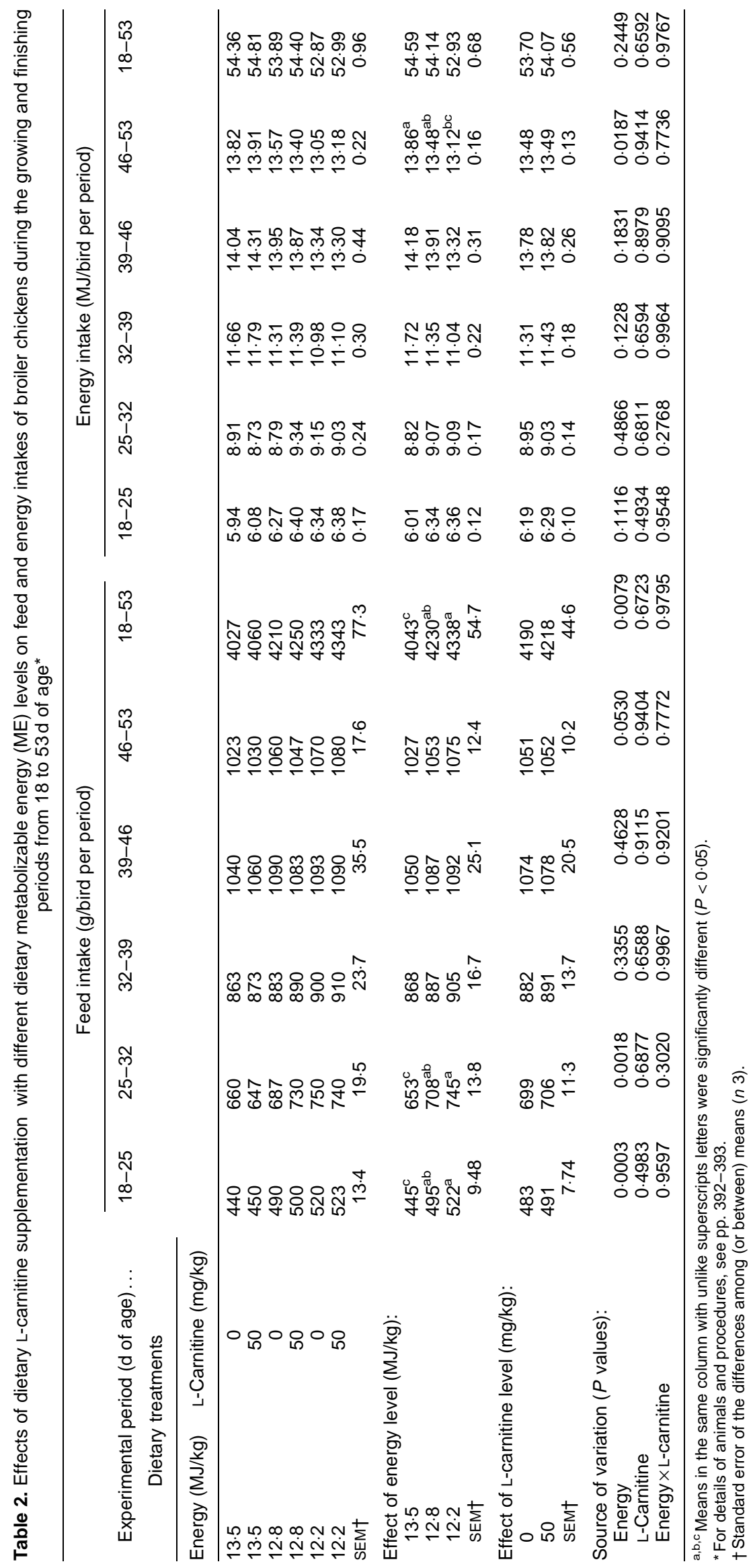


were observed during the first 2 weeks of the experimental period (18-32d of age) and over the entire experimental period. Improvements in FC in response to supplemental dietary L-carnitine were observed during the same periods, and also during the feeding period $39-46 \mathrm{~d}$ of age.

Regardless of L-carnitine supplementation, dietary energy level had a significant effect on BWG and FC (Table 3). There were significant reductions in BWG over the experimental period when dietary energy level was decreased from 13.5 to $12.2 \mathrm{MJ} \mathrm{ME} / \mathrm{kg}$ diet, except during the feeding period $46-53 \mathrm{~d}$ of age. In most feeding periods studied, the differences observed in BWG between birds fed on the highest level (13.5 MJ ME/kg diet) and those fed on the medium level $(12.8 \mathrm{MJ} \mathrm{ME} / \mathrm{kg}$ diet $)$ of dietary energy were not significant; but significant differences in BWG were observed between birds fed on the medium energy level compared with those fed on the lowest level (12.2 MJ ME/kg diet) of dietary energy. In most feeding periods examined, significant differences in FC values were found among groups of birds fed on the three dietary energy levels, with and without supplemental dietary L-carnitine. Throughout the experiment, the highest values for FC were achieved by birds fed on the highest dietary energy level, followed by those of birds fed on medium level; those birds fed on the lowest level of dietary energy had the lowest FC. There was a significant interaction between added dietary L-carnitine and dietary energy level with respect to BWG and FC during the period from 25 to $32 \mathrm{~d}$ of age (Table 3). Values for the absolute weights of carcass yield and components at $53 \mathrm{~d}$ of age are summarized in Table 4. Also, it should be pointed out that the relative weight of abdominal fat (i.e. as a proportion of total body weight) decreased considerably in response to dietary L-carnitine supplementation and decreasing dietary energy level.

Dietary energy level also had a pronounced effect on some variables of carcass yield and quality, independent of L-carnitine. Decreasing dietary energy level from 13.5 to $12.2 \mathrm{MJ} \mathrm{ME} / \mathrm{kg}$ in the grower-finisher diets of broilers resulted in significant reductions in $53 \mathrm{~d}$ live body weight and concomitant decreases in weights of eviscerated carcass, liver, breast yield (including bones), breast meat yield, thigh yield (thighs plus drumsticks with bones), thigh meat yield (meat excised from thighs plus drumsticks), total edible parts and abdominal fat contents of $53 \mathrm{~d}$-old broiler chickens (Table 4).

All other carcass variables studied were unaffected by either dietary energy level or L-carnitine supplementation. Similarly, the interaction between supplemental dietary L-carnitine and dietary energy level was not significant for all carcass variables investigated. In addition, neither L-carnitine supplementation nor dietary energy level affected the composition of the edible meat (i.e. liver, breast meat, or thigh meat) of 53-d-old broilers, in terms of its contents of DM, crude protein and diethyl ether extract. No interaction was found between supplemental dietary L-carnitine and dietary energy level for any of the proximate analyses used to evaluate the composition of the edible meat of broilers at $53 \mathrm{~d}$ of age. As the dietary treatments had no significant effects on the composition of the edible meat, these data are not presented.

\section{Discussion}

\section{Effect of supplemental dietary L-carnitine}

Theoretically, dietary L-carnitine could play a role in reducing the undesirable fat in carcasses of broiler chickens. Carnitine has a key role in facilitating the transport of long-chain fatty acids across the inner mitochondrial membrane before $\beta$-oxidation (Bremer, 1983). Thus, under conditions of L-carnitine insufficiency the transport of longchain fatty acids could be impaired. Diets supplemented with L-carnitine, therefore, should enhance the oxidation of these fatty acids, thereby decreasing their availability for esterification to triacylglycerols and storage in the adipose tissues. The reduced absolute weights of abdominal fat content (Table 4) observed in the present study in response to L-carnitine supplementation may be attributed, at least partly, to an increased rate of fatty acid oxidation within the cell (in mitochondria) induced by L-carnitine. The loss of substrate (fatty acids), in turn, could result in a reduction of hepatic lipogenic capacity, since the liver is considered as a major site of lipogenesis in poultry (Goodridge \& Ball, 1967; Brady et al. 1976; Saadoun \& Leclercq, 1983); but other factors may also be responsible for the regulation of the rate of fat accumulation in adipose tissues and muscles. In this regard, Ji et al. (1996) provided evidence to explain the mechanism by which dietary L-carnitine may alter some indices of intermediary metabolism by stimulating fatty acid oxidation in Atlantic salmon (Salmo salar). Their results suggested induction of pyruvate carboxylase (EC 6.4.1.1; or a reduction of turnover) and enhanced protein synthesis as the mechanism for carnitineinduced changes in gluconeogenesis and $\mathrm{N}$ metabolism.

The improvements in BWG of broilers observed in response to added dietary L-carnitine (Table 3) may be attributable to an improved utilization of dietary $\mathrm{N}$, achieved through more efficient fat oxidation by L-carnitine. The increased fatty acid oxidation induced by L-carnitine may result in decreased availability of long-chain fatty acids for esterification to triacylglycerols, and at the same time can raise the mitochondrial level of acetyl-CoA. Such a situation can affect the activity of pyruvate carboxylase, which is an acetyl-CoA-dependent enzyme that can supply C chains for amino acid biosynthesis (Cyr et al. 1991).

The calculated lysine and methionine (the precursors of L-carnitine) levels in the present experimental diets were adequate for broiler chickens, according to the nutrient requirements of poultry outlined by the National Research Council (1984). However, this does not include the existence of variations in the lysine and methionine contents of the experimental diets, formulated under the conditions of the current study, when compared with other diets having the same feed ingredients but grown in different geographical locations or processed by different techniques. It is possible that if the potential contents of lysine and methionine in the present experimental diets were marginally deficient or inadequate, supplementation with L-carnitine could improve the utilization of dietary $\mathrm{N}$, either directly through sparing its precursors for protein biosynthesis and other cellular functions, or indirectly by optimizing the balance between essential and non-essential amino acids within the cell. Such a situation allows for an improvement 


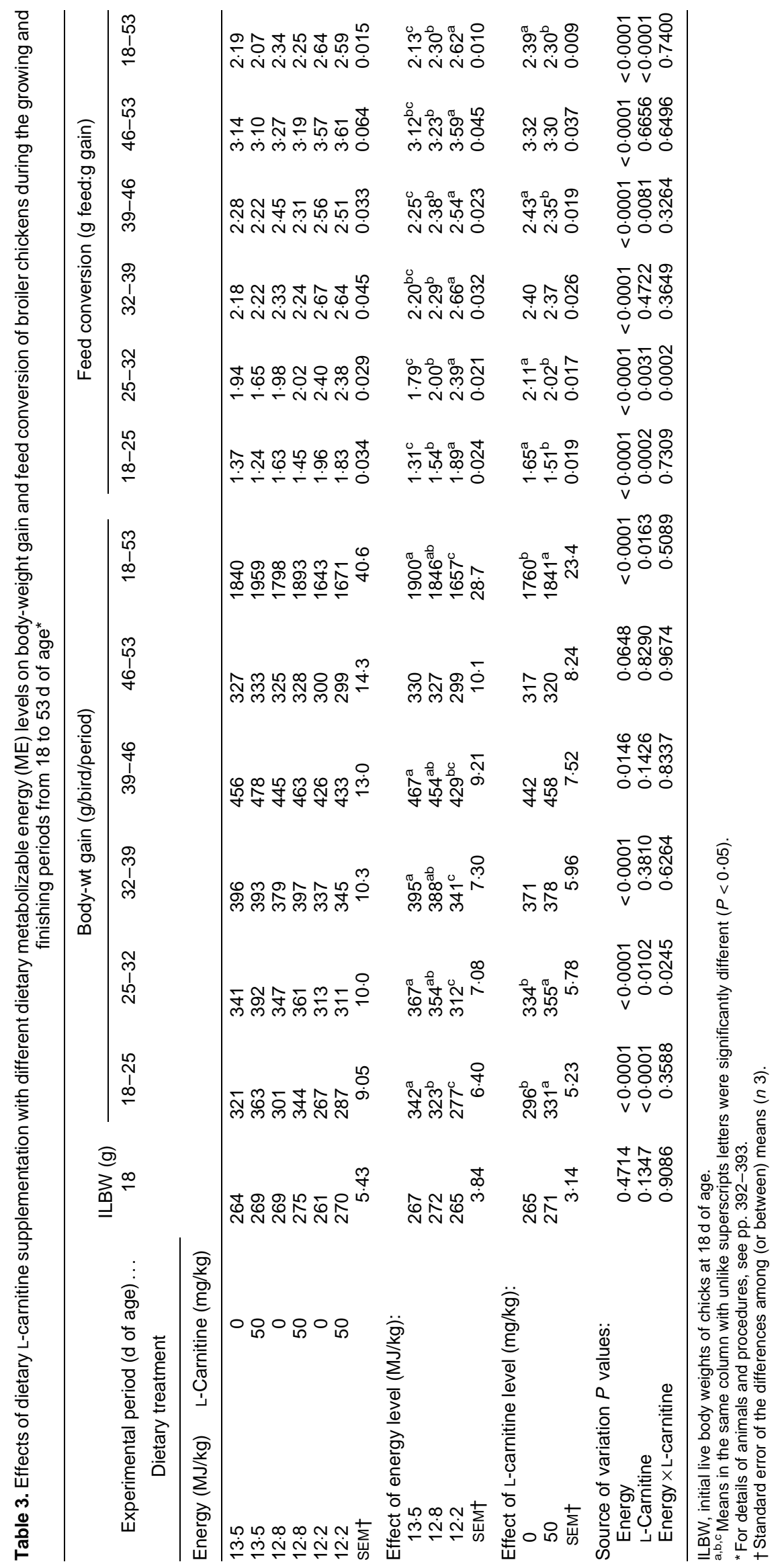


Dietary carnitine, energy and broiler growth

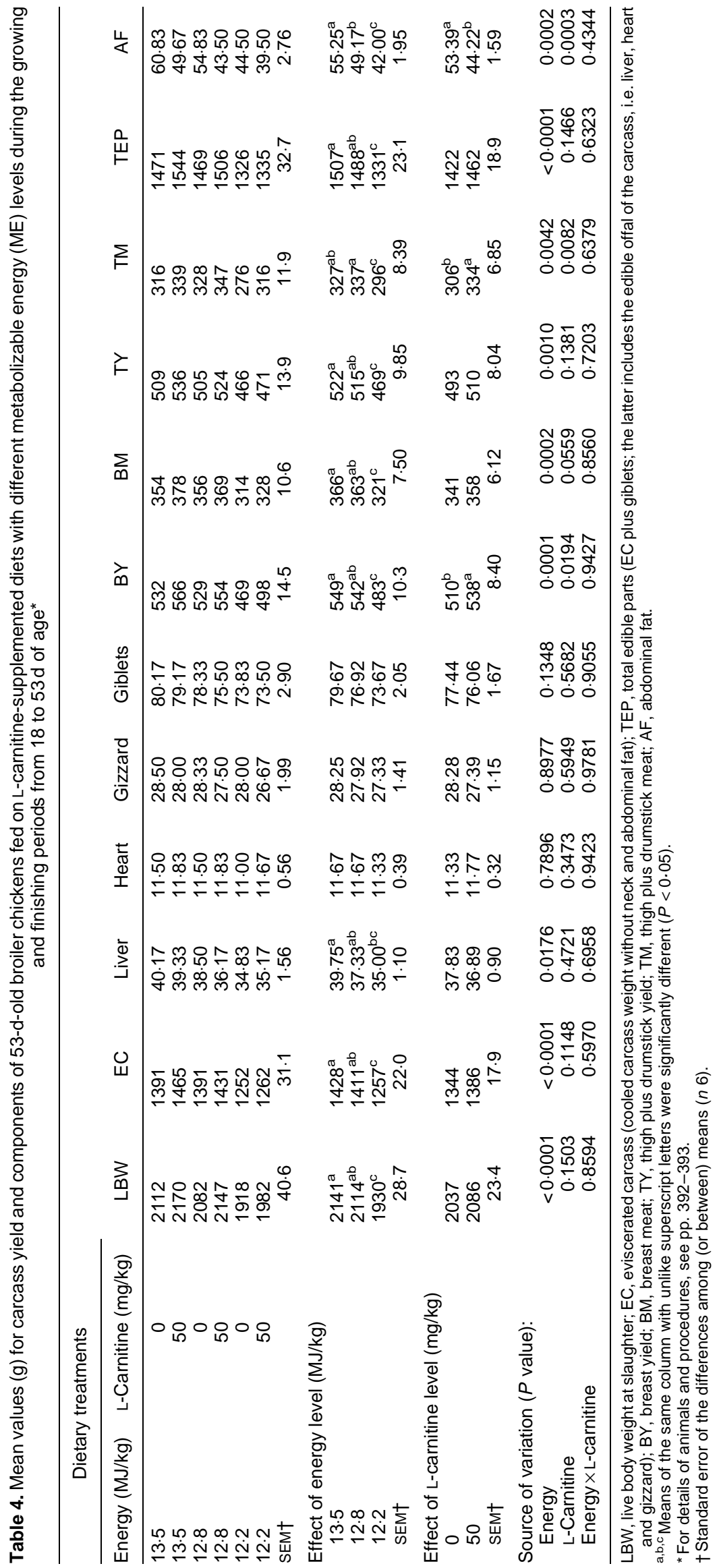


in the metabolic efficiency of dietary protein utilization and a reduction in $\mathrm{N}$ losses.

We observed positive responses in BWG of broilers to dietary L-carnitine during the first 2 weeks of the experimental period and also over the experimental feeding period. The increased rate of growth observed in the present study during the period from 18 to $32 \mathrm{~d}$ of age in response to supplemental dietary L-carnitine may imply that the requirement of broiler chickens for L-carnitine is higher during a period of rapid growth. In human subjects, Feller \& Rudman (1988) have concluded that the requirement for L-carnitine is increased by rapid growth. They have also pointed out that the biosynthetic capacity of L-carnitine is reduced by prematurity and is high in infancy. The higher BWG achieved by birds fed on diets supplemented with L-carnitine compared with controls may explain the better FC (Table 3), since feed intakes were approximately similar for the two groups, irrespective of dietary energy level.

ANOVA showed that weights of breast yield and thigh meat yield were significantly increased in response to L-carnitine supplementation, independent of dietary energy level. These responses may be attributable to superior growth in these portions of carcasses of birds fed on L-carnitine-supplemented diets compared with their controls.

Only limited information is available in the literature on the response of avian species, particularly broiler chickens, to supplemental dietary carnitine. In our two previous studies on broiler chickens, supplemental dietary L-carnitine caused significant increases in BWG and improved FC. We also observed significant reductions in abdominal fat contents of broilers, either expressed on an absolute or relative weight basis, in response to dietary L-carnitine supplementation (Rabie et al. 1997c,d). In one of these studies, broilers were fed on three levels of supplemental dietary L-carnitine $(50,100$ or $150 \mathrm{mg} / \mathrm{kg})$ from 18 to $46 \mathrm{~d}$ of age (Rabie et al. 1997d). In the second study, broilers were fed on L-carnitine-supplemented $(50 \mathrm{mg} / \mathrm{kg})$ diets of different crude protein levels $(180,200$ or $220 \mathrm{~g} / \mathrm{kg}$ from 18 to $53 \mathrm{~d}$ of age (Rabie et al. 1997c).

The results of the present study are in agreement with our previous findings for broiler chickens, and also agree with those reported by other authors for pigs, fish and foals (Weeden et al. 1991; Torreele et al. 1993; Hausenblasz et al. 1996). Weeden et al. (1991) fed L-carnitine to starter pigs at levels of 0 or $1000 \mathrm{mg} / \mathrm{kg}$ diet from 0 to 2 weeks after weaning, followed by carnitine concentrations of 0,250 or $500 \mathrm{mg} / \mathrm{kg}$ diet for the next 3 weeks. They noted an improvement in average daily gain of pigs fed on carnitine. They also found a linear improvement in feed efficiency of young pigs with increasing dietary carnitine concentration. Torreele et al. (1993) reported improvements in growth rate and FC and a reduction in body fat of African catfish (Clarias gariepius) fed on diets supplemented with L-carnitine. Hausenblasz et al. (1996) reported that BWG and degree of protein conversion (efficiency of protein utilization) achieved by foals receiving $10 \mathrm{~g}$ supplementary dietary L-carnitine/d for $78 \mathrm{~d}$ were significantly greater than those of the control group.

In contrast, Cartwright (1986) reported that performance of broilers, in terms of body weight, feed consumption, carcass fat and abdominal fat content, was not affected by feeding diet supplemented with $5000 \mathrm{mg}$ L-carnitine/kg diet from 5 to 7 weeks of age. Likewise, Barker \& Sell (1994) observed no effect of added dietary L-carnitine, at levels of 50 or $100 \mathrm{mg} / \mathrm{kg}$ diet, on performance or carcass composition of broiler chickens and young turkeys fed on low- or high-fat diets. Leibetseder (1995) investigated the effectiveness of carnitine and its precursors (lysine and methionine) in reducing the formation of abdominal fat in broilers fed on diets supplemented with 0 or $50 \mathrm{~g}$ fat/ $\mathrm{kg}$. He found that performance (BWG and FC) and abdominal fat content of broilers were not influenced by dietary carnitine (L or DL form) at a level of $200 \mathrm{mg} / \mathrm{kg}$ diet. He also reported that carnitine concentrations in liver, kidney, heart and certain skeletal muscles significantly increased in response to supplemental dietary L-carnitine. These studies may have been conducted under managerial, housing or environmental conditions different from those applied in the present study. It is possible, therefore, that the inconsistency between our findings and those of the previously-mentioned authors may be associated with the use of different protocols and time periods of experimentation. For example, Cartwright (1986) investigated dietary supplementation with L-carnitine for broilers only during the finishing period, i.e. from 5 to 7 weeks of age; in our study, supplemental dietary L-carnitine was evaluated from 18 to $53 \mathrm{~d}$ of age. In the study of Barker \& Sell (1994), 1-d-old male broiler chicks were fed on L-carnitinesupplemented diets up to $45 \mathrm{~d}$ of age, while our chicks were of mixed sex. However, it is well known that sex and age of birds are important factors affecting growth performance and carcass traits. These factors and others can interfere with the responsiveness to dietary treatments.

\section{Effect of dietary energy level}

We observed that feed intake of broilers increased significantly during the first 2 weeks of the experimental period and over the feeding period (Table 2), in response to decreasing dietary energy level below $13.5 \mathrm{MJ} \mathrm{ME} / \mathrm{kg}$, both with and without supplemental L-carnitine. This response concurs with the concept that, under ad libitum feeding conditions, birds tend to eat primarily to satisfy their energy requirements. The observation that dietary energy level had no effect on energy intake of broilers throughout the experimental period (Table 2), except during the period 46-53 d of age, may support this theory. During the feeding period 46-53 d of age birds fed on the lowest dietary energy level consumed slightly more feed (not significant) than those fed on the higher energy levels. However, the energy intake of birds fed on the lowest energy level was significantly lower than that of birds fed on the highest dietary energy level. These results agree with those reported by Jackson et al. (1982a), who have found that feed intake of male broilers, reared to $49 \mathrm{~d}$ of age, was significantly reduced with increasing dietary energy level above $12.55 \mathrm{MJ}$ (3000 kcal) ME/kg.

In the present study, independent of added dietary L-carnitine, the lower BWG achieved by birds fed on the lowest level of dietary energy compared with the higher energy levels could be attributable to a less efficient 
utilization of dietary energy, which may be due to a higher level of inclusion of wheat and/or the absence of supplemental fat in their diet (Table 3). Our results agree with those obtained by Jackson et al. $(1982 a, b)$, who found that increasing dietary energy level resulted in significant increases in body weight of broilers.

The results presented in Table 3 also demonstrated that FC decreased when dietary energy level increased, independent of supplemental dietary L-carnitine. This finding is in accordance with those reported by Jackson et al. (1982a,b), Deaton \& Lott (1985) and Leeson et al. (1996b).

Data shown in Table 4 suggest that the lower weights of some carcass variables achieved by birds fed on the lowest energy level, in most cases, compared with those of birds fed on the higher energy level, might be related directly to the lower body weight of the former, independent of L-carnitine supplementation. The reduction in abdominal fat content of broilers in the present study agrees with the results reported by Deaton \& Lott (1985), who found that abdominal fat contents of broilers were decreased when the energy content of the diet decreased, and that the limit of reduction was dependent on the energy contents of starter and finisher diets as well as sex and age of birds.

\section{Dietary L-carnitine $\times$ energy interaction}

Significant interactions between supplemental dietary L-carnitine and dietary energy level were noted for both BWG and FC of broilers during the second week of the experimental period (Table 3). These interactions may suggest that supplemental L-carnitine was more effective at the highest level of energy $(13.5 \mathrm{MJ} \mathrm{ME} / \mathrm{kg})$ than at the lower levels $(12.8$ or $12.2 \mathrm{MJ} \mathrm{ME} / \mathrm{kg})$ of dietary energy. These results indicate a synergistic effect for L-carnitine at the higher energy levels in relation to BWG and FC of broilers. Such a response is probably not related to the energy level itself, but may be due to differences in the fatty acid composition of dietary fat; i.e. the results might have been influenced by the composition of dietary fat, since L-carnitine is mainly of importance for the oxidation of long-chain fatty acids.

It is concluded that supplemental dietary L-carnitine has growth-promoting and fat-lowering effects in broiler chickens fed on diets with different energy levels. However, under the conditions of the present study, decreasing the dietary energy level to $12.2 \mathrm{MJ} / \mathrm{kg}$, although beneficial in reducing abdominal fat, was detrimental to growth and carcass yield of broilers.

\section{Acknowledgement}

The authors are grateful to LONZA Ltd., Basel, Switzerland, for providing L-carnitine supplement used in this study.

\section{References}

Association of Official Analytical Chemists (1980) Official Methods of Analysis, 13th ed. Washington, DC: AOAC.

Barker DL \& Sell JL (1994) Dietary carnitine did not influence performance and carcass composition of broiler chickens and young turkeys fed low- or high-fat diets. Poultry Science 73, 281-287.
Baumgartner M \& Blum R (1993) L-Carnitine in animal nutrition. In Vitamine und weitere Zusatzstoffe bei Mensch und Tier (Vitamins and Other Supplements for Humans and Animals), pp. 413-418 [G Flachowsky and R Schubert, editors]. Jena, Germany: Friedrich-Schiller Universität.

Brady L, Romsos DR \& Leveille GA (1976) In vivo estimation of fatty acid synthesis in the chicken (Gallus domesticus) utilising ${ }^{3} \mathrm{H}_{2} \mathrm{O}$. Comparative Biochemistry and Physiology 54, 403-407.

Bremer J (1983) Carnitine: metabolism and functions. Physiological Reviews 63, 1421-1480.

Cartwright AL (1986) Effect of carnitine and dietary energy concentration on body weight and body lipid of growing broilers. Poultry Science 65, Suppl. 1, 21 Abstr.

Cyr DM, Egan SG, Brini CM \& Tremblay GC (1991) On the mechanism of inhibition of gluconeogenesis and ureagenesis by sodium benzoate. Biochemical Pharmacology 42, 645654.

Deaton JW \& Lott BD (1985) Age and dietary energy effect on broiler abdominal fat deposition. Poultry Science 64, 2161-2164.

Duncan DB (1955) Multiple range and multiple F tests. Biometrics 11, 1-42.

Fancher BI \& Jensen LS (1989) Influence on performance of three to six-week-old broilers of varying dietary protein contents with supplementation of essential amino acid requirements. Poultry Science 68, 113-123.

Feller AG \& Rudman D (1988) Role of carnitine in human nutrition. Journal of Nutrition 118, 541-547.

Goodridge AG \& Ball EG (1967) Lipogenesis in the pigeon: in vivo studies. American Journal of Physiology 213, 245-249.

Hausenblasz J, Ács M, Petri Á \& Mézes M (1996) Effect of L-carnitine on some metabolic parameters of foals. Állattenyésztés és Takarmányozás 45, 397-403.

Jackson S, Summers JD \& Leeson S (1982a) Response of male broilers to varying levels of dietary protein and energy. Nutrition Reports International 25, 601-612.

Jackson S, Summers JD \& Leeson S (1982b) Effects of dietary protein and energy on broiler performance and production costs. Poultry Science 61, 2232-2240.

Jensen JF (1984) Methods of Dissection of Broiler Carcasses and Description of Parts, pp. 32-61. Cambridge, UK: Papworth's Pendragon Press.

Ji H, Bradley TM \& Tremblay GC (1996) Atlantic salmon (Salmo salar) fed L-carnitine exhibit altered intermediary metabolism and reduced tissue lipid, but no change in growth rate. Journal of Nutrition 126, 1937-1950.

Khan L \& Bamji MS (1979) Tissue carnitine deficiency due to dietary lysine deficiency. Triglyceride accumulation and concomitant impairment in fatty acid oxidation. Journal of Nutrition 109, 24-31.

Leeson S, Caston L \& Summers JD (1996a) Broiler response to energy or energy and protein dilution in the finisher diet. Poultry Science 75, 522-528.

Leeson S, Caston L \& Summers JD (1996b) Broiler response to diet energy. Poultry Science 75, 529-535.

Leibetseder J (1995) Studies of L-carnitine effects in poultry. Archives of Animal Nutrition 48, 97-108.

Lettner VF, Zollitsch W \& Halbmayer E (1992) Use of L-carnitine in the broiler ration. Bodenkultur 43, 161-167.

National Research Council (1984) Nutrient Requirements of Poultry, 8th revised ed. Washington, DC: National Academy Press.

Rabie MH, Szilágyi M \& Gippert T (1997a) Effects of dietary L-carnitine on the performance and egg quality of laying hens from 65 to 73 weeks of age. British Journal of Nutrition 78, 615-623. 
Rabie MH, Szilágyi M \& Gippert T (1997b) Influence of supplemental dietary L-carnitine on performance and egg quality of pullets during the early laying period. Állattenyésztés és Takarmányozás 46, 457-468.

Rabie MH, Szilágyi M \& Gippert T (1997c) Effects of dietary L-carnitine supplementation and protein level on performance and degree of meatiness and fatness of broilers. Acta Biologica Hungarica 48, 221-239.

Rabie MH, Szilágyi M, Gippert T, Votisky E \& Gerendai D (1997d) Influence of dietary L-carnitine on performance and carcass quality of broiler chickens. Acta Biologica Hungarica 48, 241-252.

Rebouche CJ (1991) Ascorbic acid and carnitine biosynthesis. American Journal of Clinical Nutrition 54, 1147S-1152S.

Rebouche CJ (1992) Carnitine function and requirements during the life cycle. FASEB Journal 6, 3379-3386.

Rinaudo MT, Curto M, Bruno R, Piccinini M \& Marino C (1991) Acid soluble, short chain esterified and free carnitine in the liver, heart, muscle and brain of pre- and post-hatched chicks. International Journal of Biochemistry 23, 59-65.

Saadoun A \& Leclercq B (1983) Comparison of in vivo fatty acid synthesis of the genetically lean and fat chickens. Comparative Biochemistry and Physiology 75B, 641-644.

Sándor A, Kispál Gy, Kerner J \& Alkonyi I (1983) Combined effect of ascorbic acid deficiency and underfeeding on hepatic carnitine level in guinea-pigs. Experientia 39, 512-513.

Santulli A \& D'Amelio V (1986) Effects of supplemental dietary carnitine on growth and lipid metabolism of hatchery-reared sea bass (Dicentrarchus labrax L.). Aquaculture 59, 177-186.

Schuhmacher A, Eissner C \& Gropp JM (1993) Carnitine in fish, piglets and quail. In Vitamine und weitere Zusatzstoffe bei Mensch und Tier (Vitamins and Other Supplements for Humans and Animals), pp 407-412 [G Flachowsky and $\mathrm{R}$ Schubert, editors]. Jena, Germany: Friedrich-Schiller Universität.

Statistical Graphics Corporation (1991) Statgraphics, Version 5.0 Reference Manual. Rockville, MD: Statistical Graphics Corporation.

Summers JD \& Leeson S (1984) Influence of dietary protein and energy level on broiler performance and carcass composition. Nutrition Reports International 29, 757-767.

Szilágyi M, Lindberg P \& Sankari S (1992) Serum L-carnitine concentration in domestic animals. In Proceedings of the 5th Congress of International Society of Animal Clinical Biochemistry, pp. 389-391 [A Ubaldi, editor]. Parma, Italy: Boehringer Mannheim.

Torreele E, van der Sluiszen A \& Verreth J (1993) The effect of dietary L-carnitine on the growth performance in fingerlings of the African catfish (Clarias gariepinus) in relation to dietary lipid. British Journal of Nutrition 69, 289-299.

Weeden TL, Nelssen JL, Hansen JA, Fitzner GE \& Goodband RD (1991) The effect of L-carnitine on starter pig performance and carcass composition. Journal of Animal Science 69, Suppl., 105 Abstr. 